\title{
Research on Influencing Factors of Sports Violence
}

\author{
Weimin Wang ${ }^{1}$, Anshun Chen ${ }^{2}$ \\ ${ }^{1}$ Sports College of Jiangxi Normal University, China \\ ${ }^{2}$ Quanzhou Normal University, China
}

Keywords: sports violence; philosophy; humanities.

\begin{abstract}
In this paper, literature review is used to summarize the influencing factors of sports violence. The author believes that more research on sports violence now focuses on the human body, lack of humanistic care, too much to see only negative influences and lack of double-sided or multi-faceted understanding of things. Sports violence brings social instability. It is a stumbling block to our pursuit of a faster, higher and stronger path. However, it can be regulated by studying the causes of sports violence and specific and efficient means and restraints to reduce its production and impact.
\end{abstract}

\section{Introduction}

With the development and evolution of mankind's long river, sport has become more and more closely with us. Running Wind has become a trend; sweating has become a fashion; and muscle has become an aesthetic. This all shows that sports have injected oxidants into modern life and people enjoy the nourishment they bring to sports. It is true that the world is not perfect, but we are striving for this goal. Mankind constantly strives to make breakthroughs - to explore - to change - to realize, to make every possible move from time to time, from heaven to earth, irrespective of yours and mers, and to endlessly move forward and forward.

The same is true of sports, he gives people physical strength, spiritual enrichment. Sports violence, however, gave it a layer of gauze. By reviewing the core journals in January 2013 (January 2017) and searching for "Sports Violence," very few articles were retrieved and most of them were written on the surface of the last century's articles and competitions. There is a lack of deep source of sports violence By, meaning. This article will start from the multi-angle, multi-subject, multi-level understanding-evaluation-coping method and initially construct the overall idea of sports violence.

\section{Sports Violence}

\subsection{What is sports violence?}

Sports violence refers to the behavior of individuals who are attacked by certain anger after being frustrated in a sports environment and satisfy two conditions at the same time, causing physical or psychological harm to others. The attackers' Successful outcome of the results [1 Zhou Jiaji, Zhu Xuelei, Yang Meng bamboo. Sports in the attack and violence [J] Sports Research, 2002, (04): 20-22.]. As sports violence is more abstract and broad, most scholars will use the specific; sports attacks; sports deviant behavior; fans riots; stadium violence; duel competitions, competitive sports, such as the unethical phenomenon of words, this article will be treated as a physical violence Interpretation.

\subsection{Physical violence double-sided.}

The dismantling of sports violence from the meaning of words is the violence that takes place within the concept of sports behavior. In this way, we understand that we all can say that it is negative and should be avoided. But when we look closely at the regular boxing, Sanda, wrestling and other sports, sports violence seems to contain profound philosophical thinking. 
The contents of sports violence are complex and can not be understood in a one-sided way. The essence of sports violence is discarded.

\subsection{Research Status At Home and Abroad.}

Sports violence in Europe and the United States in the 1970s more research, but most from the biological level to understand the impact of sports violence, contempt of its social, human and other factors. With the dawn of the era of science and technology, people are more rational and seek the true value and significance of tracing the source, exploring and pursuing their lives. In all fields, including what we call sports violence, human factors that have infiltrated society are gradually being understood, recognized, and studied.

The study of sports violence in China is a little later than in the western world, mainly because of the backwardness of competitive sports. It is the first time since 1984 that the Olympic Games in Los Angeles officially appeared in the Olympic Games as a national identity. Although the gold medal is only inferior to that of the two major camps, the United States and the Soviet Union, the elite sports do not represent the sports for all, and our sports are just beginning to sprout . Until now we can only say that we are a sports power rather than a sports power. At a time when the situation was grim in both domestic and foreign situations, sport was more for politics. Therefore, a deeper study on sports (sports violence) was also on the right track. Domestic scholars also took the incident of violence on football (May 19, 1985) as an example on May 19, 1985, and started the study of sports violence in China The precedent.

\section{Different Areas - Sports Violence}

\subsection{Philosophical Interpretation.}

The philosophy of modern humanism in our country started relatively late, and with the end of the Cultural Revolution, the humanistic and cultural currents only prevailed in China. Studying sports violence scholars is even less. After having the honor to study "the existence of life behavior - the clue of sports philosophy, history and culture", I have given me a lot more for life, more for sports, more for sports violence Unique understanding and exploration of perspectives.

Physical aggression is human nature, he is natural instinct instinct, but also to maintain the health and life, the quality of life has the ability to save. Ancient Roman sports fighting is seen as the Champions League athletics, Gladiator is the hero of ancient Roman culture, its roots lie in the pursuit of the value of life. When the country is in danger, they can be fearless, give their lives for freedom, honor, and nation. At that time, the social value of duel athletics was not only for maintaining social stability, promoting economic development, promoting infrastructure construction and improving the management level of sports. At the same time, he has elements such as wildness and enterprising spirit, hard work and passion, and has effectively promoted the progress of civilization and the development of society.

Athletics combine the duel elements of life together and become a body art. Making man and nature coexist harmoniously; barbarism and civilized coexistence; coexistence of body and soul; in athletics, the urge to duel has been liberated by civilization and athletics has become part of civilization; strong physical avenues have been found and the frailty has been defeated; Close to nature, physical fitness has become the object of repeated practice, and become a living skill; the perpetual guidance of life, will be given to the competitive direction, and become enterprising, hardworking and create ethical characterization; , The appearance of competition, the respect of honor can find the basis of theory, the principle of action and the ideal plasticity [existence of life-behavior - philosophy of sports, history and culture of clues p312].

In the opposition and unity of sports subjectivity, violence and regularity, sports violence is the solution to life violence. Sports rules are the epitome of civilized order and the exercise field of social order. Letting social violence enter the sports space is Self-help behavior of human civilization. Sports rules allow violence to be limited to its own sphere, and violence is translated into the motivation for victory. In sports activities, the tendency of violence will be restrained and restrained. 
The spirit of the rules is advocated to be followed. Violence causes the value of the rules to come out. [Opposites of Unity: Contradictions and Contradictions of Sports Themes].

\subsection{Law debate.}

The definition of responsibility after the occurrence of sports violence is a topic that the academic circles have been arguing endlessly. The definition of the two main responsibilities is to produce the main body of sports violence, one through sports groups to punish the other is the occurrence of great social problems through public security departments to punish. In the current case of sports violence, a handful of public security departments are involved in the mediation, negotiation and punishment generally conducted by sports organizations.

Excessive intervention by the public security department will make the competition lose some competition (intense), so that the game becomes too stable and not conducive to the competition, the expansion of the project, the development of sports. But if the game does not have the scale, the athletes themselves is a kind of injury. Many existing sporting event regulations explicitly stipulate that a major accident will be punished by public security authorities rather than a simple, even symbolic, fine suspension. Due to the different scales and circumstance of various kinds of sports violence, it is very difficult to define them qualitatively and the intensity of punishments is also different. However, it is believed that with the soundness of a society ruled by law, sports violence law will give more attention.

\subsection{Social Speculation (Traditional Culture).}

Since the ancient times, European cultures since the ancient Greek civilization - challenges, self-confidence, freedom, or the mainstream of the Chinese civilization, the golden mean, Confucianism - conservative, hardworking, peace, they jointly created the world's cultural diversity. Read through history, we are fortunate to be in their own time, from the "fire" of the baptism. West to the establishment of the ancient Greek city-states, east of the First Emperor Qin unified world, thousands of years of mankind river just thousands of years of war countless. At all times and in all countries, our common creed has its own expansion and resistance. It is also the traditional ideological trend that accompanies the society. People are not far behind and do not want to fall behind because they know that backwardness will be beaten. People's psychological confrontation and is infinitely enlarged, infiltration of all-encompassing, of which there is physical education. A social trend of thinking about sports violence is in full swing.

\subsection{Body Call.}

Man is a complex body of life, both emotions, but also the potential of the body instinct. According to Freud's ontology, man has the desire to live and die, the desire to die involves self-destruction, and the harm to himself can be averted by attacking others. Moreover, Bandura believes that all human acquired behavior is the result of learning. Through observation-imitation-intensive-acquisition, he emphasizes the importance of human cognition.

To put it simply, I believe we have a memory of the former NBA Rockets center Mutombo and his iconic gesture of swinging his index finger after covering his opponent makes everyone remember. Of course, the "ancient" era of the NBA did not pay enough attention to this action, leading to the back of the game due to several contradictions between players on both sides of similar actions, thus gradually regulate the league to kill the move. However, only Uncle Mu owns the "Shame Index" amnesty, his position and reputation we self-evident. Nearly a decade is nba in the development of China's fastest-growing market ten years, the depth and breadth of its impact we have to admire. The development of China's NBA market is a living example of global economic integration. To most people, he is mutually beneficial and win-win. But here I have to mention a figure - Ji Zhe (CBA Beijing Shougang basketball team). In the game against Qingdao, the former NBA superstar Tracy McGrady put a one-third vote after swinging its index finger, which makes the elbow elbow the former to show their anger. This is a typical star model behavior, we can not guess what its purpose is, but at least this star model behavior does give some small players some bad effects. The culture of "Uncle $\mathrm{Mu}$ " we always remember, but the behavior of those who later need to re-examine, discuss the 
body of physical violence call for us to continue.

\section{Different Sports - Sports Violence}

\subsection{To Attack Opponents for the Winning Means Project.}

Projects such as wrestling, boxing and Sanda are the products of civilization sustained by the "de-violence" of ancient sports. Although such sports are bloody and cruel, within the scope of sound rules, we see more of them as "Violence aesthetics."

Of course, there are no shortage of athletes in the sport after defeating opponents (the rules do not allow knockdown continued to beat), continue chasing opponents, even after the referee waved to terminate the game but also make up a few punches, and even worse Before the pre-game press conference, they started to play a role in each other. It is because of the direct confrontation of the sport that sports violence occurs more frequently in the field.We have to look at the problem in two, as does sports violence.

\subsection{Multi-Person Area To Play Free Technical And Tactical Projects.}

The typical representatives of this type of sport: football; ice hockey; basketball. Here to talk about the ice hockey this sport, take relatively well-known NHL Grand Alliance, they will acquiesce in the form of boxing players duel, of course, there is a lot of stress here. The duel has become a gentleman on the ice hockey court, to avoid even more potential violence. Sometimes the scene is too calm, the fans will not buy live, it can be said that some fans are directed at the duel. Here, we have to think of the ancient Roman duel culture mentioned above, perhaps, this is the continuation of the latter's culture.

Football, basketball are more technical and tactical, fierce confrontation, the results are unpredictable features. And the stadium accommodate a large number of fans, the atmosphere is often very hot stadium, a precise long pass; a strange second pass; a wonderful goal; a superb dunks will lead fans cheer crazy cheer. And in the basketball arena also host the DJ's "fan flames" and the hot basketball baby performance, clamoring for each person's hormones surge. In this environment, the field team extremely excited, the decline in the execution of technical and tactical, non-standard action can easily lead to over-excited behavior. A stone waves provoked Melaleuca, stadium violence occurred from time to time, everyone should be self-examination. Sports violence is not blindly to solve, but should be at the right time; the right place; the right object; to do the right thing, this is something we are worth to try.

\subsection{Network Project.}

The typical representative of the net movement tennis, volleyball, badminton and many other small ball project. Judging from the level of development, the best players of these projects are concentrated in Europe, the United States and East Asia. Their living standards are relatively high and their social literacy is relatively high. Tennis was even more acclaimed as a nobility project earlier in the year, and such a high rating was enough to make the project more civilized. China is badminton, table tennis and other countries with the highest level of balls, the Chinese people stress the golden mean. In the same way, outstanding athletes in our country really give exemplary leadership to their peers.

Second, the points of such competitions are based on the bureau, the venue will be interchangeable during the game, interchangeable serve, suspension and so on. It also gives intense competition to adjust the atmosphere appropriately. The center line of the players on the field axis, each playing technical and tactical, non-aggression and no more conversation, this is also the reason why such games less physical violence.

\subsection{Personal Performance Type Project.}

This type of typical representatives of gymnastics, diving, free skating and other projects. Most of its characteristics is the competition environment only one person or two pairs of competing, the 
venue will be accompanied by beautiful music rendering. Players on the field not only to complete their chosen action, the referee will give on-site performance and degree of difficulty scoring. Therefore, team members are the best state of mind, to show their best side to the judges and spectators. Athletes in the game there is no direct confrontation, are determined by the scoreboard in the background, these are the direct cause of this type of sports almost no physical violence.

\section{Summary}

Man and society are an integral part of the interaction. Man is conscious. He can play a role in society. The society can reach a consensus or multiple consensuses through a collection of all-inclusive people and react to the subjective initiative of man. And material decision consciousness, consciousness reaction to the material is similar to the feedback mechanism. In the same way, sports (violence) permeates the society and causes instability. However, reasonable sports violence can emerge as a social safety valve. It not only has no harm to society, but also appears to be a sublimation of humanity, pursuit of sports and enjoyment of sports.

\section{References}

[1] ZHOU Jia-Ji, ZHU Xue-Lei, YANG Meng-Zhu. Attack and Violence in Sports [J]. Sports Science Research, 2002, (04): 20-22.

[2] LIU Xin-ran, WANG Yuan, XIA Yuan-min. Opposition Unity: The Contradiction and Interpretation of Physical Subjectivity [J]. Journal of Chengdu Sport University, 2016, 42 (05): 40-46. 